\title{
Research on Teaching of Arc Welding Robot based on Simufact Welding Simulation
}

\author{
Min $\mathrm{Hu}$ \\ Jiangsu province xuzhou technician institute \\ Xuzhou, Jiangsu 221151, China \\ 331947080@qq.com
}

\begin{abstract}
This paper introduces the function and characteristics of Simufact simulation software, and applies the simufact simulation software in the teaching of arc welding robot in technical colleges and universities. This software is used to understand the parameters of welding current, wire feeding speed, welding speed and so on. The welding parameters can be mastered more intuitively through the simulation effect. The influence of weld forming, stress and deformation can be more effective and quick to help students master how to set reasonable welding parameters according to welding base materials, weld size, welding conditions and so on.
\end{abstract}

Keywords-Simufact welding; Welding process parameters; Arc welding robot teaching

\section{INTRODUCTION}

Arc welding technology has been widely used in important occasions of various steel structures since its application in the late 19th century. With the development of intelligent manufacturing, arc welding robots have gradually become the advantages of high efficiency, low cost, and good welding quality. The main force is widely used in various fields such as pipelines, ships and automobiles. Among them, gas shielded welding is one of the most important production technologies in welding production, and it is also the most widely used welding technology. Carbon dioxide gas shielded welding automatic welding is to be obtained [1]. Good welding results, welding process is the decisive factor.

Since conform to the manufacturing industry, Xuzhou, Jiangsu Province Technician College since 2010 to open the application and maintenance of professional welding robots, welders training more than 7,000 , about 5,000 people engaged in welding robot operation, currently more than 400 students welder, in order to raise adaption enterprise. Development of demanding welding robots to operate skilled talents, improve students efficiently, quickly, and at low cost. Set welding parameters to improve teaching quality welding robots, welding simulation study will simufact applied to the welding robot application and maintenance of professional teaching。

There are many current welding simulation tools. The most commonly used tools are multi-functional finite element analysis software such as ansys, Abaqus, and Marc [2]. Although these tools can produce better analysis results, they are not specifically applied to welding simulation software.
These software have higher requirements for users and need to program out each process, so it is more suitable for experts and for general users. It takes too much time and effort. Special welding simulation software with simufact welding and sysweld, and finite element simulation software.

Compared to these dedicated welding simulation software programming requirements low, it does not require users to complete simulation program. During the welding process is complex welding temperature field, stress field, interaction of tissue state, undergoes complex physical change, for students throughout the simulation, not only have an intuitive feeling of welding parameters on the weld impact, and You can acquire all the welding process parameters to establish interaction relationship. Therefore, it is of great significance to use Simufact welding simulation software to simulate the weld forming process in the teaching process of welding robot application and maintenance in technical colleges.

\section{THE ESTABLISHMENT OF SIMUFACT WELDING FINITE ELEMENTS}

The typical operation steps of welding simulation are: (1) Importing meshed parts of welding assembly (2) Establishing a simulation model (3) Defining welding process parameters (4) Performing simulation (5) Displaying results and performing post-processing Importing meshed welding Components should use a variety of grids, where a finer mesh around the weld is required to accurately obtain the high gradient temperatures produced during the welding process, but if the welding software has an incompatible meshing algorithm, the imported Parts can be meshed independently without restrictions on compatibility [3]. The design of a compatible grid for complex welded components is very difficult and time consuming. Therefore, incompatible meshing algorithms are very important. After solidworks modeling, Hypermesh is used to divide the meshes and save them. Good modeling of simulation models helps reduce preprocessing time and the user interface must be intuitive. At the same time, it is required to draw the welding components step by step, such as pre-defined groups of welding parts or fixtures, which can be used to help the user to construct the welding structure.

When Simufact Welding finite element software is used for the simulation analysis of the weldment, it is necessary to define the solver, welding assembly, boundary conditions, number of welding guns, and tracking points. The analysis 
solver is used Iterative Sparse Solver setting parameters including total simulation time, the respective flow time, time step, mesh refinement level, and the friction coefficient of the tracking point. In addition, there are welding components, which refer to the three-dimensional welding structure divided by the mesh. At the same time, material definition of the welding structure and the welding torch is required, including initial temperature, heat transfer coefficient, material properties, and geometric parameters. Boundary conditions mainly refer to welding restraint methods, including support, fixation, and clamping. In the calculation process, the boundary needs to be $2 \mathrm{D}$ or 3D meshed. Need to define the welding torch parameters, including the welding path, initial temperature and heat transfer coefficient, welding material properties, torch angle and direction[4]. Post-processing results analysis, the software can always look at the calculation results, not only can display the stress, deformation cloud map, as well as tracking point results over time curve.

The material used for professional training and application of welding robots is Q345B. Its chemical composition is shown in Table 1. This material is comparable to the S355J2G3 model material in the welding software simufact welding material library. S355J2G3 Young's modulus of the material, Poisson's ratio, density, specific heat, thermal expansion coefficient versus temperature, and flow stress plastic strain curves, strain curve CCT, TTT and phase change curve by Anisotropic Syndrome In-house material library available.

TABLE I. Q345 chemical composition

\begin{tabular}{lllllllllllll}
\hline $\mathrm{C}$ & $\mathrm{Si}$ & $\mathrm{Mn}$ & $\mathrm{P}$ & $\mathrm{S}$ & $\mathrm{Nb}$ & $\mathrm{V}$ & $\mathrm{Ti}$ & $\mathrm{Cr}$ & $\mathrm{Ni}$ & $\mathrm{Cu}$ & $\mathrm{N}$ & $\mathrm{Mo}$ \\
\hline 0.2 & 0. & 1.7 & 0.03 & 0.03 & 0.07 & 0.15 & 0.2 & 0.3 & 0.5 & 0.3 & 0.0 & 0.1 \\
& 5 & & 5 & 5 & & & & & & & 12 & \\
\hline
\end{tabular}

The model consists of welds (parts), fixtures, clamps and low plate weldments 1 and 2 with geometries of $150 \mathrm{~mm} \mathrm{x}$ $80 \mathrm{~mm} \times 5 \mathrm{~mm}$ and $150 \mathrm{~mm} \times 60 \mathrm{~mm} \times 5 \mathrm{~mm}$ respectively. Q345, the physical model is imported into Hypermesh for volume meshing, as shown in Figure 1. Then the partitioned solid mesh is imported into Simufact Welding for assembly and assignment. The constraints of weldments 1 and 2 are divided into two groups: fully constrained and Not completely constrained, the ambient temperature is $20^{\circ} \mathrm{C}$, the welding current is $170 \mathrm{~A}$, the arc voltage is $18 \mathrm{~V}$, the welding speed is $9 \mathrm{~m} / \mathrm{h}$, the welding rod diameter is $\varphi 4.0$, the arc length is controlled within the range of $2 \mathrm{~mm} \sim 4 \mathrm{~mm}$, the vector coordinate of gravity direction is $\mathrm{X}, \mathrm{Y}, \mathrm{Z}(0,0,-1)$. At room temperature, the yield strength os of Q345 is $345 \mathrm{MPa}$, and the tensile strength $\sigma \mathrm{b}$ is $470-630 \mathrm{MPa}$. The training results are shown in Figure 2

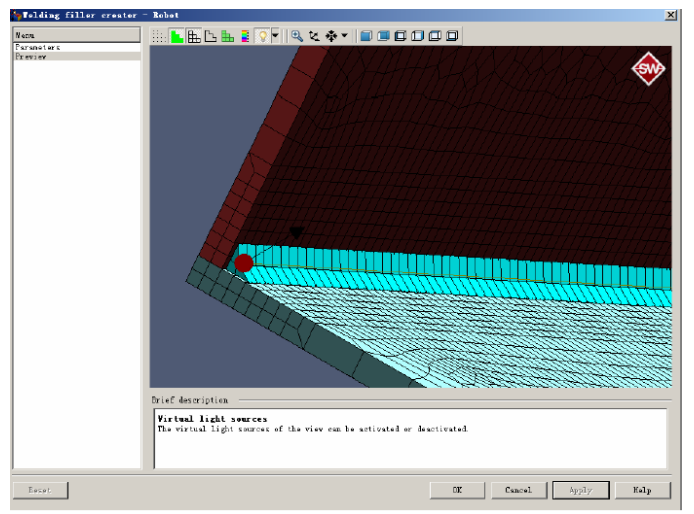

Fig. 1 Grid partition

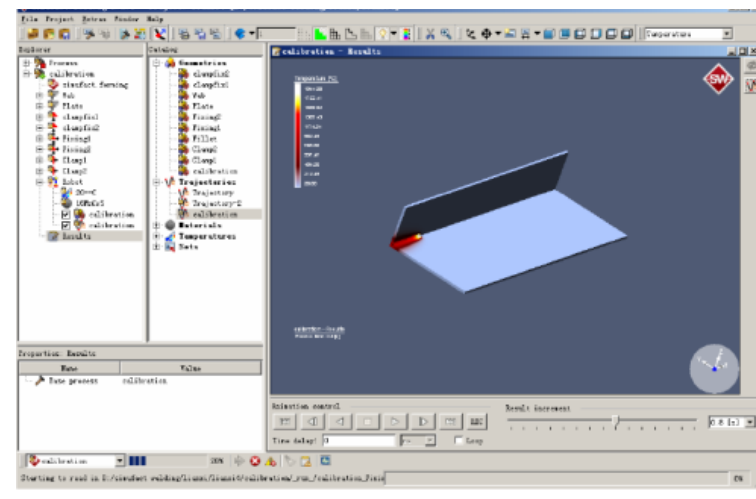

Fig. 2 Simulation results

\section{RELATIONSHIP BETWEEN WELDING PARAMETERS AND WELD FORMING OF ARC WELDING ROBOTS}

In the arc welding robot welding process, the welding parameters such as welding speed, voltage, current, preheating temperature, the restriction of the number of other different welding torch configuration process, the main process parameters is essential reasonable selection influence on the welding quality.

In the process of welding, students lack the understanding of the interaction between welding parameters. Through this simulation operation, we can enhance the understanding and intuitively feel the relationship between the change of the process parameters and the weld formation, which is of great guiding significance to the improvement of the teaching and actual production of welding robots.

\section{A. Welding speed}

Welding electrode moves during the unit time from the welding direction is referred to as a welding speed, its size will directly determine the amount of heat input size. Welding speed, the higher the peak temperature of the nodes, due to the long residence time on the workpiece, especially for sheet 
metal parts, the workpiece can easily be welded through, causing the collapse of the workpiece, and the welding speed is high, the heat source The time spent on the workpiece is short and it is prone to weld impermeability. Therefore, it is very important to choose a reasonable welding speed when welding workpieces.

\section{B. Welding current}

Welding current is an important welding parameter, it has a big impact on the shape and size of the weld, and it has a decisive effect on the weld melt. In this case, the speed of the deposition and the positive ratio of the weld to the welding current, it also affects the width of the fuse. It needs to be reminded that, when the welding current reaches a certain level, it will easily lead to such defects as burning through of the parent material and welding leakage, and the welding current is too large, the welding heat input increases, the welding deformation is large, and the welding cracks are generated. However, if the weld is too small, it will create an unsoldered, slag, and so on, and the weld is not good. In general, when welding current selection is carried out, the base material is not burnt through, but also ensured to be welded through as the precondition, and is selected according to the specific conditions such as droplet transition form, groove form, thickness of the base material $\mathrm{W}$ and wire diameter. The permitted current range is different for different wire diameters.

\section{Welding voltage}

Welding voltage is the energy of melting wire, which has direct influence on the stability of welding process. Too high or too low arc voltage will have adverse effects on weld forming, weld spatter and metallurgical reaction. When arc voltage is increased, the width of the weld is obviously increased, and the depth and the surplus height are slightly reduced, the fusion zone of the weld and the addition of the weld and the mechanical property decrease. It's important to note that, for a certain amount of wire, there's a very good arc of the arc, and the arc of the arc is too high to create a gas hole, a flapper and an unstable arc; Too low arc voltage often leads to poor weld formation and even solid short circuit of wire and molten pool. In particular, in order to obtain good weld forming, the welding current and arc voltage should be matched reasonably. Generally, the welding current is small and the corresponding arc voltage is low. When the welding current is large, the larger arc voltage should be selected correspondingly.

\section{Dry extension length of welding wire}

The dry extension length of the wire is the length of the wire extending from the conductive nozzle to the workpiece. It is one of the basic conditions to ensure the stability of the welding process to keep the extension length of the welding wire unchanged when welding with $\mathrm{C} 2$ gas protection. The extension length of the wire is closely related to the preheating effect of the wire, and the preheating effect of the wire has a direct influence on the welding parameters and welding quality. The longer the wire is stretched out, the stronger the preheating effect, and vice versa. Under the condition of a certain wire feeding speed, when the wire extends for a certain length, the resistance preheating effect is small, the arc power is large, the melting depth is large, and the splash is small. When the wire is extended long, the resistance preheating action is strong, the arc power is small, the burn depth is shallow and the splash is large [5]. Usually, for the welding wire with different diameters and different materials, during the welding process, the extension length of the welding wire is generally 10-15 times of the diameter of the wire.

\section{WELDING STRESS PRODUCTION.}

Welding stress and deformation is a result of weldment caused by uneven heating when welding, welding, hot action due to the arc, arc accessories around the metal temperature significantly expand, heating part of the metal, at different levels according to the heat, to the corresponding elongation, without being heated metal parts to maintain the original length, so the elongation is hampered by cold metal heating, limits the freedom of elongation of heating metal parts, then heat the metal to produce compressive stress, tensile stress and the cold metal part. Cooling, due to the heating of metal has produced when heated compression deformation, therefore the length of the heated metal than the length of the short, but at this point, the metal around the would hinder its shortened, results in the weld metal is heated to produce the tensile stress, which are produced by the compressive stress in the surrounding metal, will buy the simulation time for the $6000 \mathrm{~s}$ and is divided into four stages, the first stage of welding process, the rest of the stage for the cooling process), the first stage: $0 \sim 60 \mathrm{~s}$, the second stage: $60 \sim 1300$ s, the third stage: $1300 \sim 5900$ s, the fourth stage: $5900 \sim 6000$ s. In $60 \sim 1300$ s time, welding fusion line under uncertain and full constraints method of equivalent stress $0 \sim 60$ s time corresponding equivalent stress significantly, in the $300 \mathrm{~s} \sim 1200 \mathrm{~s}$ time, weldment completely out of most of the fusion line location constraint method of equivalent stress is greater than the weldment corresponding value under uncertain constraint method, starting from the $1200 \mathrm{~s}$, weldment completely under the corresponding equivalent stress method is less than weldment incomplete constraint method under the corresponding value. In the time between 1300 and 5900s, the equivalent stress at the position of most fusion lines under the method of incomplete binding of welded parts is greater than the corresponding value under the method of complete binding of welded parts. The high temperature duration under the method of incomplete constraint is more stable than that under the method of complete constraint. In $5900 \sim 6000 \mathrm{~s}$ time, welding pieces of incomplete constraint method under most of the fusion line location of the residual stress is greater than the yield strength of Q345 at room temperature, welding method under fully controlled most of the fusion line location of residual stress is less than the yield strength of Q345 at room temperature. 


\section{SUMMARY}

Simufact welding simulation is used in the teaching of welding robots instead of the traditional theoretical teaching. Students can grasp the knowledge of welding process parameters from the influence of changes in welding parameters on weld forming, which not only shortens the experiment time, but also improves the efficiency of the practice. By learning the simulation operation flow of sim ufact, the application ability of simulation software is improved. This study not only helps to realize the integrated teaching of welding robots, but also plays an active guiding role in the analysis and numerical calculation of other welding parts in the future.

\section{REFERENCES}

[1] Wang Lining Simufact.welding analysis of deformation of ring welding [J]. Shanghai large and medium sized motor, 2017 (3): 10-13.

[2] Jiang Chuanbao, Wang Feng. Simulation analysis of side girders welding based on simufact.welding software $[\mathrm{J}]$. China Science and Technology Expo, 2013 (20): 150-151.

[3] Ma Xiaoming, Lu Guanpeng. Numerical simulation of welding residual stress of CRDM socket based on Simufact [J]. welding technology, 2017 (5): 51-54.

[4] Yuan Sibo, Cheng Jun, Han Jianye, et al. Finite element simulation analysis of stress and strain in a new titanium alloy seamless tube during rolling process [J]. Guangdong chemical industry, 2017, 44 (8): 62-64.

[5] Li Bo, Yang Zujian. Numerical simulation of rolling process of GH3044 profiled ring based on Simufact [J]. modern machinery, 2016 (2): 22-27. 